Office of Waste Isolation Union Carbide Corporation Nuclear Division Oak Ridge, Tennessee

\title{
Thermal Guidelines for a Repository in Bedrock
}

Prepared by

Parsons Brinckerhoff Quade \& Douglas, Inc.

New York 


\section{DISCLAIMER}

This report was prepared as an account of work sponsored by an agency of the United States Government. Neither the United States Government nor any agency Thereof, nor any of their employees, makes any warranty, express or implied, or assumes any legal liability or responsibility for the accuracy, completeness, or usefulness of any information, apparatus, product, or process disclosed, or represents that its use would not infringe privately owned rights. Reference herein to any specific commercial product, process, or service by trade name, trademark, manufacturer, or otherwise does not necessarily constitute or imply its endorsement, recommendation, or favoring by the United States Government or any agency thereof. The views and opinions of authors expressed herein do not necessarily state or reflect those of the United States Government or any agency thereof. 


\section{DISCLAIMER}

Portions of this document may be illegible in electronic image products. Images are produced from the best available original document. 


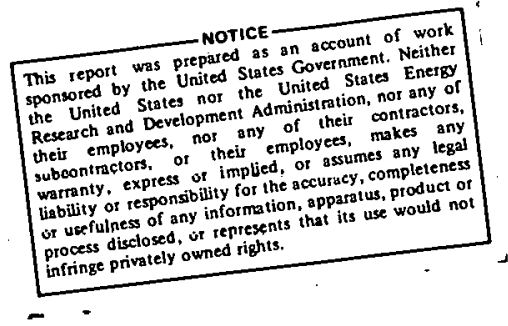

This informal document contains information which is preliminary and may be fragmentary or of limited scope. The assumptions, views, and conclusions expressed in this document are those of the author and are not to be interpreted as those of Union Carbide Corporation, Nuclear Division, or USERDA.

This report was prepared as an account of work sponsored by the United States Government. Neither the United States nor the Energy Research and Development Administration, nor any of their employees, nor any of their contractors. subcontractors, or their employees, makes any warranty, express or implied, or assumes any legal liability or responsibility for the accuracy, completeness or uselulness of any information, apparatus, prondirst or process disclosed, or represents that its use would not infringe privately owned rights.

\section{Thermal Guidelines for a Repository in Bedrock}

Prepared by Parsons Brinckerhoff Quade \& Douglas, Inc. New York 


\section{PARSONS BRINCKERHOFF INTERNATIONAL, INC.}

\section{Engineers - Architects • Planners}

One Penn Plaza, 250 West 34th Street • New York, N.Y. 10001 • 212-239-7900 • Cable: Parklap, New York • Telex WU12-5441 • RCA 232117

Octaber 15,1976

Mr. L. L. McCauley

Building 9102-2

Office of Waste Isolation

Union Carbide Corporation

Oak Ridge, Tennessee 37803

Re: Contract No. TG $86 \mathrm{Y} 16504 \mathrm{~V}$

Dear Mr. McCauley:

In compliance with the terms of Contract No. TG $86 \mathrm{Y}$ 16504V, we are pleased to submit herewith 25 copies of our final report "Thermal Guidelines for a Repository in Bedrock".

We have enjoyed our association with the Office of Waste Isolation and we appreciate the opportunity we have had to be of service to your office and to the nuclear power industry.

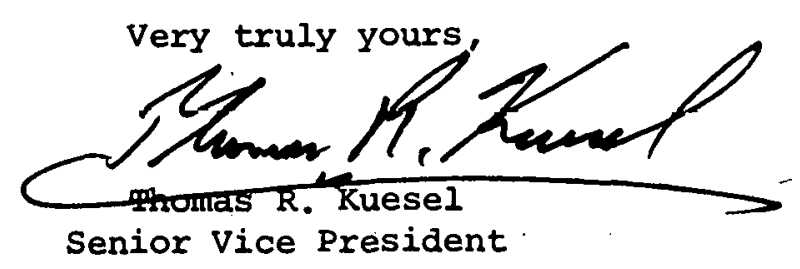

TRK/sw

enc.

CC: A. L. Boch

S. C. Mat thews 
: LIST OF TABLES

$\underline{\text { TABLE }}$

1 Elastic properties of granites versus temperature change

2 Elastic properties of a charcoal granite

3 Elastic properties of Solenhofen limestone versus temperature change

4. Average chemical composition of rocks.

5 Rock thermophysical properties and behavior $\underline{\text { PAGE }}$

20

20

22

24

26

i 
1 Effect of temperature on creep

2 Stress-strain curves for repetto siltstone deformed dry in compression at 1000 and 2000 bars confining pressure and at different temperatures

3 Engineering classification for intact rocksummary plot for lgneous rocks

4 Representation of brittle fracture mechanism for quartzite in uniaxial gradually increased compression

5 Thermal conductivity of holocrystalline rocks 18

6 Specific heat values of high $-\mathrm{SiO}_{2}$ rock types

7 Engineering classification for intact rocksummary plot for sedimentary rocks

8 Engineering classification for intact rocklimestone and dolomite 


\section{INTRODUCTION}

This report summarizes the findings of a study conducted by Parsons Brinckerhoff to develop general thermal guidelines for the underground storage of canisters containing high level nuclear waste. The report contains general thermal guidelines for spacing canisters in three types of rock - shale, limestone, and granite; a survey of thermophysical rock properties and rock mechanical behavior; and a recommended approach for determining rigorously the thermal design criteria for the storage facility. This recommended approach would couple rock mechanics and thermal considerations in a transient, finite element model capable of simulating the excavation and canister emplacement sequence. In recognition of the nascent stage of the waste storage program, we've closed this report with suggestions for future research and for future analytical and experimental efforts.

The canisters of nuclear waste will produce significant quantities of heat from radioactive decay. The storage facility, therefore, must be designed in a manner that will permit this heat to be dissipated safely and efficiently. crucial to this design is proper canister pitch.

The two major constraints on canister pitch are the maximum allowable temperature of the stored nuclear waste and the overall structural integrity of the underground facility. 


\section{METHODOLOGY}

\section{A. Background of the Problem}

The maximum temperature of the stored waste inside the canister - one of the two major thermal constraints discussed above - will be governed by the rate of heat generation inside the canister, the conductivity of the waste, the spacing between canisters, the geometry and boundary conditions of the storage facility, and the thermomechanical properties of the surrounding medium.

The problem of canister spacing must also be viewed in light of the effect of elevated temperatures on the structural integrity of the host rock of the storage facility. The elevated temperature in the rock may cause:

1. Softening of the pillars and accelerated creep rate.

2. Intergranular cracking.

3. Possible loss of wall integrity by thermal surface spalling.

4. Expansion of entrapped gases and moisture in sedimentary, porous formations.

5. Possible chemical reactions and phase changes.

6. Propagation of bedding plane discontinuities with the resultant effect on rock soundness as reflected in indices such as the Rock Quality Designation (RQD).

Ventilation requirements were viewed as resulting from the thermal analysis, rather than as an additional constraint on canister spacing.

It has been determined elsewhere [81] that the temperature of the stored waste should not exceed the temperature used in the waste solidification process. This temperature range between $550^{\circ} \mathrm{C}$ and $1100^{\circ} \mathrm{C}$, depending on the process used. Thermal constraints pertaining to the structural integrity of the facility are far more difficult to determine. They depend for the most part on the viscoelastic behavior of the rock media, rock thermophysical properties, and the recoverability criterion for the canisters. These issues are discussed in detail in section III, below.

When Cheverton and Turner [28] investigated the possibility of storing the canisters in salt deposits, their main thermal criterion in the long term related to rock mechanics concerned possible fracture of the shale layer above the salt [27]. This concern stemmed from knowledge of the 
characteristics of a specific prototype site in Lyons, Kansas. It is the contention of the present study, which is concerned with the generic thermal implications of storage in shale, limestone, and granite, that all possible and reasonable rock mechanic failure modes should be investiagated.

In particular, the disposal of hot radioactive waste material in shale, limestone, or granite has more technical problems associated with it than does the disposal in salt deposits. These rocks have special characteristics not found in salt, including low conductivity, high porosity, anisotropy, and inhomogeneity. These properties and the possibility of inelastic behavior of the rock under elevated temperatures render difficult an analysis of thermoelastic/ inelastic deformation. There is also a strong indication that there is thermomechanical coupling in these three rocks. That is, heating affects the deformation, and thermal properties in turn may be influenced by strain. Thus, it is crucial to understand fully the rock properties and behavior, and to determine how far the assumption of continuum media can be applied to shale, limestone, and granite.

Clearly, the temperature dependency of rock thermophysical properties, particularly conductivity and strength, together with the complex coupling relationship between temperature and rock behavior, require a sophisticated but practical solution technique. Tending to support this conclusion are two other complicating phenomena: the transient aspect of heat conduction and the surface to boundary convective heat transfer occurring at the room surfaces.

\section{B. General Treatment of the Heat Transfer Problem}

The prediction of heat transfer from the hot radioactive waste materials contained in the canisters buried in the geologic formation to the heat sink of the surrounding rock medium is a complex problem. To solve it, two general types of heat transfer prediction models have evolved physical models and mathematical models. The former are based on either scale model laboratory tests or prototype in-situ tests. These models are effective and particularly useful in complex geologic formations involving chemical reactions and phase changes.

Most mathematical models are based on solution of the general heat flow equilibrium equation for the temperature distribution within the geologic formation. These models are valid only if geologic formations can be treated as a true continuum and if thermomechanical coupling of the rock 
behavior is one-way, i.e., if heat transfer problems can be treated independent of rock mechanics problems. Three methods are available for solving the general heat flow equilibrium equation - exact methods, approximate analytical methods, and approximate numerical methods.

In almost all of the problems for which an exact solution is possible, the thermal properties of rock are taken to be constants, independent of both temperature and spatial location [25]. If the thermal properties depend on temperature, the problem becomes nonlinear, and the temperature field must be determined by approximate methods. An approximate analytical method of solution requires that an initial temperature profile be assumed before the solution can be carried out. Two of the more commonly used techniques are the Laplace-variational method [54] and the integral method [41]. Analytical methods of solution are generally capable of solving a wide variety of one-dimensional heat problems with temperature-dependent thermal conductivity.

The most commonly used numerical method for solving the heat equation is the finite difference method [78]. In this implicit method, the governing differential equation is replaced by a time dependent set of simultaneous algebraic equations. In recent years, the finite element method has gained widespread use in the analysis of complex structural/thermal problems [66]. This method is desirable for solving the heat flow problem because the same model can be used for both the rock stress and heat transfer analysis and can account for the thermomechanical coupling between the two.

In reviewing the above-mentioned complicating phenomena of heat flow in the three types of rock and the ability of each of the three types of mathematical models to simulate the real world situation, we conclude that approximate numerical methods are best suited for predicting the temperature field in the underground nuclear waste storage facility.

Further discussions among Parsons Brinckerhoff staff, U R. D. Cheverton [27] of ORNL, G. Llewellyn [52] of XCC-ND Engineering, and Professor Giovanni Barla of the Columbia University School of Mines [3] have served to verify that the problem is not amenable to exact solution by closed form analytical functions. In fact, use of the idealized problem approach would require such gross approximations that the results would bear no relationship to reality and would therefore be of no practical value. 


\section{Properties Table}

This study has concentrated on formulating, in as much detail as possible, the structure of the relationships between temperature and rock behavior that govern the selection of appropriate thermal criteria. The preliminary results of this formulation were then used to develop general guidelines for spacing the canisters.

It is important to note that although the most mathematically rigorous models, including the finite difference method and finite element method, offer the potential for providing the most reliable numerical solutions, simpler, less mathematically rigorous approaches often yield results that are more consistent with empirically observed behavior. One such approach, which we've turned to for this study, uses laboratory and field data, numerical results from similar geothermal problems, and professional judgment and experience. The following steps comprised the application of this approach to the present study:

1. Identification of Rock Properties and Behavioral Parameters. All geologic-mechanical-thermal properties of the rock that affect the heat flow were identified. Possible behavioral phenomena affecting the structural integrity of both the underground storage facility and the surrounding rock medium were investigated. Last, a literature survey was made to determine the range of all identified rock properties and behavioral parameters.

2. Development of Geologic-Mechanical-Thermal Table. The data compiled in step 1 were assembled into the table of properties shown in Table 5 . The development of the geologic-mechanical-thermal table for the four types of rock - granite, limestone, and shale, plus salt - provides valuable information on a) the role each property and parameter plays in the heat flow in geologic formations, and on b) the coupling between thermal and mechanical behavior which affects the integrity of underground cavaties. The table, with salt included as a basis of comparison, was then used to evaluate the following rock characteristics and behavior:

a. rock physical properties - elastic and inelastic physical constants and their sensitivity to temperature, as well as the stress-strain parameters which affect the mechanical behavior of rock;

b. rock thermal parameters - thermal conductivity, heat capacity, density, and thermal expansion of rock, as a function of temperature, pressure and rock porosity;

c. chemical reaction and phase changes of the rock in the immediate vicinity of the canister; 
d. rock mechanical behavior - probability of occurrence and the rate of development of creep, surface spalling, plastic flow, and fragmentation due to the influence of overburden and elevated temperatures.

3. Formulation of Thermal Guidelines for Canister Spacing. Thermal guidelines for canister spacing were developed based on the rock property and behavior information provided in the table. This information was then combined with our professional judgment and experience concerning the cause and effect relationship between rock properties and behavior on the one hand, and heat flow and structural integrity on the other. From this process evolved preliminary, generic guidelines for spacing the canisters in the different rock media. Although these are relative, order-of-magnitude guidelines only, they provide an understanding of the overall behavior of the geologic formation as influenced by the presence of the stored hot radioactive waste materials. The guidelines also provide the information needed for preliminary engineering design of the facility. 
III. THERMOPHYSICAL ROCK PROPERTIES AND ROCK MECHANICAL BEHAVIOR

A. The Coupling of Thermal and Mechanical Rock Behavior

The rock mechanics investigations for Project salt Vault $[38,39,56,72]$ consisted of in-situ measurements of the deformation of the salt in the experimental rooms and pillars and throughout the existing mine, laboratory creep tests on model salt pillars, and the development of a theoretical model for predicting pillar deformation as a function of load and temperature. The theoretical model could also predict the behavior of the surrounding salt strata under changing conditions of support and thermal expansion. These investigations, described by Starfield and McClain. [72], considered strain as a function of stress and temperature history, for a given set of rock properties.

In reality, however, the relationship between the temperature gradient and rock stress/strain is a reciprocal one. While it is true that rock strain will be affected by temperature, it is also true that the thermal conductivity of the rock varies with rock density, grain orientation, and the RQD of the rock. Since these three factors are in turn affected by rock stress and strain, it is clear that the thermal conductivity and the resultant temperature gradient are themselves functions of rock stress and strain. Hence, any rigorous analysis of the underground facility should couple the thermal problem with the rock mechanics problem and iterate between the two until the solution converges.

In the discussion that follows, the thermal properties of rock and rock mechanical behavior are treated separately, for simplicity. It is emphasized, though, that in the real world there is strong interaction between the two and this interaction must be accounted for in any rigorous analysis.

\section{B. Thermal Conductivity}

The thermal conductivity (and thermal diffusivity) of the geologic medium surrounding the canisters of stored waste is the most important thermophysical variable affecting the temperature distribution of the underground facility. It will strongly influence the thermal stability of both the stored waste and the surrounding geologic formation. As discussed above, the latter influence will, in turn, have a bearing on the overall structural integrity of the entire underground facility.

Generally, the thermal conductivity of a geologic formation is dependent on the following factors: 
Temperature

- Pressure

- D́ensity

- Porosity and water content

- Degree of isotropy and homogeneity

- Presence of discontinuities, i.e. cracks and fractures, in the rock microstructure.

The effects of temperature on the thermal conductivity of sedimentary rocks, such as shale and limestone, are substantial, although they may be expected to be less than the effects of porosity and water content. The thermal conductivity of crystaline rocks, such as granite, is less sensitive to temperature. ordinarily, most granites, limestones, sandstones, and slates show a decrease in thermal conductivity with increasing temperatures. Should this decrease occur in the geologic formation surrounding the waste storage facility, the temperature in the facility could increase by a greater extent than would be expected from computations based solely on the average conductivity of the medium at ambient temperatures.

Pressure can increase conductivity significantly in dry, porous materials. However, the effects of increasing pressures above that necessary to compact the material tend to diminish exponentially. These effects can be more important in sedimentary material than in igneous rocks because of the different nature of the two rock structures. The effects of pressure on the thermal conductivity of sedimentary material can be mitigated by the presence of water, since water is relatively incompressible and tends to act as a thermal conducting medium between the particles of aggregated material. Consequently, the effects of pressure are more important in dry, porous materials, and in other situations pressure is only a minor, third-order effect.

Density, along with heat capacity, is used to derive the thermal diffusivity of a material from its thermal conductivity. The density and the heat capacity are of no influence, however, after the temperature distribution of the geologic formation has reached a steady state condition.

The effect of porosity on the thermal conductivity of granite and other crystalline rocks is negligible due to the nature of the structure of these rocks and their minimal pore water content. Sedimentary material, however, can vary widely in porosity, and porosity can have a strong influence on conductivity. The effects of porosity can be both direct (since the 
conductivity of materials varies with density) and indirect (through the effects porosity has on the possible water content). The effect of pressure on conductivity is strongly dependent upon water content: the thermal conductivity of dry material will be much more strongly influenced by pressure than will be the conductivity of saturated material.

Thermal conductivity in sedimentary formations is strongly influenced by the pore water content of the rock. If the rock is allowed to heat up, the fluid may be irreversibly driven out, causing a significant decrease in the thermal conductivity. Moreover, if the temperatures are high enough to cause rapid fluid migration; hydrofracturing of the rock may result [81;p.24.64]. Should this prove to be the case, the geologic formation might no longer be considered an acceptable disposal medium.

The bedding planes of sedimentary rock formations and the foliations of igneous rock usually exhibit significantly higher thermal conductivity in the direction of the strata compared to the direction perpendicular to the strata. This difference may be as high as 30 to 40 percent. In addition, the conductivity of granite will vary with crystal orientation, being much higher in the direction of the crystalline axis than against it.

The presence of discontinuities and joints, in both sedimentary and crystalline rock media, will cause a reduction in the effective thermal conductivity from what it would be if the media were idealized as perfectly continuous and homogeneous. It should be noted that the effect on thermal conductivity of all the above factors will be most pronounced in the immediate vicinity of the canisters.

Available Data. The thermal conductivity of various rock types has been the subject of many investigations in recent years. As a result, an extensive literature exists on the subject. A survey of the findings reveals that thermal conductivity can vary considerably between different rock types and even within the same rock type. This is dependent on all the factors outlined above, and these influencing factors, being far from uniform, can show extreme variations.

Shale, limestone and granite are among the most common of rocks and their thermal conductivities have been fairly well catalogued, based primarily on core samples brought up from drilling operations and tested in laboratories. This has made possible the establishment with some confidence of a thermal conductivity range for each rock type.

***In the discussion that follows, thermal conductivity is given in units of $10^{-3} \mathrm{cal} / \mathrm{cm}$. sec. ${ }^{\circ} \mathrm{C} . * * *$

Shale

Bullard [24], in 1939, found thermal conductivities of 4.4 and 6.6 in two samples of shale brought up from 4190 feet 
and 6457 feet. Benfield [31], in an extensive series of measurements on 31 specimens found thermal conductivities to range from 2.8 to 5.6. These were taken from depths between 1000 feet and 8780 feet. Continuing the work of Bullard, Mossop and Gafner [59] found thermal conductivities of 4.7 to 6.8 in six samples of shale taken from depths of 1804 feet to 4418 feet in the Orange Free State. Sass, Lachenbruch and Munroe [69] obtained values of 6.7 to 8.4 for 22 samples brought up from 2425 feet to 9675 feet. All these measurements were done at laboratory temperatures between $20^{\circ} \mathrm{C}$ and $45^{\circ} \mathrm{C}$. No study could be found that measured the variation of a sample of shale with temperature; however, Sass, Lachenbruch and Munroe adjusted their thermal conductivities for in-situ temperatures using the temperature coefficients of thermal resistivity determined by Birch and Clark [22] for rocks. of similar minerology. This had the effect of lowering the thermal conductivity. Since the in-situ temperatures were higher than the laboratory temperatures, the thermal conductivity of shale was shown to decrease with increasing temperature.

With respect to pressure, Clark [3I] has found that the thermal conductivity of a specimen of uncompressed shale, ordinarily 3.9, increased by ten percent when compressed to 10,000 psi. This suggests that the thermal conductivity of shale increases with pressure, a trend that is generally confirmed by the fact that shale taken from greater depths has a higher thermal conductivity, in most cases, than shale taken from shallower depths.

Lawson [49], in his report, established an overall thermal conductivity range of 3.8 to $\sim 7$ for shale. Our findings extend this slightly to 2.8 to 8.4

\section{Limestone}

The thermal conductivity of limestone is the most extensively documented of the three rocks studied. It has been measured as a function of temperature, pressure, porosity, and water content.

Poole [31] reports that the thermal conductivity of limestone fell from 5.7 at $20^{\circ} \mathrm{C}$ to 3.2 when the temperature was increased to $350^{\circ} \mathrm{C}$. Bridgman [3I] has found that thermal conductivity drops from 5.2 at $30^{\circ} \mathrm{C}$ to 4.5 when the temperature was increased to $75^{\circ} \mathrm{C}$. Similarly, Ensor's [31] work shows thermal conductivity of 5.4 at $0^{\circ} \mathrm{C}$ versus 4.9 at $100^{\circ} \mathrm{C}$. Finally, Birch and Clark [22], in measuring thermal conductivity at $0^{\circ} \mathrm{C}, 100^{\circ} \mathrm{C}$ and $200^{\circ} \mathrm{C}$, found values of $7.2,5.5$ and 4.8 . The results of these four independent studies show quite clearly that the thermal conductivity of limestone decreases with increasing temperature in all cases even though the actual values of thermal conductivity may differ from sample to sample for the same temperature. 
Pressure effects on thermal conductivity were investigated by clark [31] for three samples of limestone of different porosity. Just as with shale, increasing pressure increases thermal conductivity, and the more porous the limestone the more its thermal conductivity increases upon compression. For example, a specimen of 3.4 percent porosity, which had a thermal conductivity of 5.0 uncompressed, increased to 5.7 under 10,000 psi, a rise of 14 percent. Meanwhile, for a specimen of 43 percent porosity, the same pressure increase caused the thermal conductivity to increase from 2.1 to 2.6, a rise of 25 percent.

Clark also examined the effects of water saturation. Water saturation raises the thermal conductivity of the rock but makes the thermal conductivity much less sensitive to pressure changes. A specimen's thermal conductivity went from 5.0 dry to 6.2 wet but remained at 6.2 when compressed to 10,000 psi. Similarly, another specimen of 13.2 percent porosity had an initial thermal conductivity of 4.4 dry which went up to 5.0 wet. Under 10,000 psi, the thermal conductivity of the dry sample increased to 4.7 , a rise of seven percent, while the thermal conductivity of the wet sample increased to 5.1 , a rise of only two percent.

Thomas, Frost and Harvey [77] did a more extensive study of porosity and the effects of water saturation. The thermal conductivity was found to decrease linearly with porosity. with water saturated samples having greater thermal conductivities than the dry samples. Dry samples had thermal conductivities ranging from 7.2 at zero percent porosity to 2.9 at 35 percent porosity. Water saturated samples ranged from. 7.4 to 4.1 over the same porosities.

Additional measurements were done by Coster [31], Misener [31], and Sass, Lachenbruch and Munroe. They found values of 5.2 mean on 21 samples, 4.7 to 8.0 range on 11 samples, and 8.2 to 12.4 on 21 samples, respectively. All these values were measured in the range of $20^{\circ} \mathrm{C}$ to $25^{\circ} \mathrm{C}$.

\section{Granite}

The effect of porosity on the thermal conductivity of granite is negligible in comparison with its effect on shale and limestone. Granite's composition and crystal structure, however, add complications. Birch and Clark [22] have done a study on the effects of mineral composition, and their findings indicate some correlation between quartz content and high thermal conductivity. A sample with 30 percent quartz had a thermal conductivity of 8.4 at $0^{\circ} \mathrm{C}$ while one with only 19 percent quartz gives a value of 5.8. This is possibly due to the formation of relatively long chains of quartz crystals which facilitate the conduction of heat. 
Again, thermal conductivity was found to decrease with temperature increase. Birch and Clark [22] investigated this effect most thoroughly, taking measurements at a number of points from $0^{\circ} \mathrm{C}$ to $300^{\circ} \mathrm{C}$. Thermal conductivities ranged from 8.4 to 5.1 over three samples of granite. The temperature range was later widened by Moiseyenko, Sokolova and Istomin [58]. Their thermal conductivites ranged from 5.2 at $20^{\circ} \mathrm{C}$ to 2.3 at $1000^{\circ} \mathrm{C}$, near the melting point of granite, to 2.7 at $1300^{\circ} \mathrm{C}$. The rise in thermal conductivity after melting is attributable to the change in physical properties induced by melting.

Additional determinations were made by Birch [21] and by Clark and Niblett [31]. In an extensive series of measurements on 59 samples of colorado granite at $30^{\circ} \mathrm{C}$ and at $2500 \mathrm{psi}$, Birch found a mean thermal conductivity of 7.9 with a standard deviation of .41. Clark and Niblett found. values ranging from 6.2 to 9.0 in examining 12 samples at $20^{\circ} \mathrm{C}$.

Correlation Equations:. In addition to empirical measurements, the literature survey revealed that some attempts have been made to establish equations, through statistical analysis of experimental results, that would explain the variations in thermal conductivity. Dmitriev, Derbenev and Goncharov [37] have developed such an expression for predicting variations of thermal conductivity with temperature, up to $600^{\circ} \mathrm{C}$. They claim an accuracy of five to eight percent:

$$
\lambda=\lambda_{\theta} k_{1}-\left[\frac{(T-30) 2.15}{T}-e^{\frac{-T}{300}}\right] \mathrm{A}
$$

where $\quad \lambda=$ thermal conductivity in $\mathrm{Kcal} / \mathrm{m} . \mathrm{h} .{ }^{\circ} \mathrm{C}$

$$
\begin{aligned}
& \lambda_{0}=\text { thermal conductivity at } 50^{\circ} \mathrm{C} \\
& k_{1}=\text { coefficient representing laminations of the rock: } \\
& \qquad \begin{aligned}
k_{1} & =1 \text {, parallel to laminations } \\
k_{1} & =.75-.93, \text { perpendicular to laminations }
\end{aligned}
\end{aligned}
$$

$\mathrm{T}=$ temperature in ${ }^{\circ} \mathrm{C}$

$A$ is a constant for each rock type:

$A=0.38$, limestone
$A=0.20$, granite 
Assad [1] has developed a similar equation for predicting thermal conductivity as a function of porosity and the thermal conductivity of the fluid saturating the pores:

$$
\mathrm{K} / \mathrm{k}_{1}=\left(\mathrm{k}_{2} / \mathrm{k}_{1}\right)^{\mathrm{m}}
$$

where

$$
\begin{aligned}
\mathrm{k}= & \text { thermal conductivity of fluid saturated rock } \\
\mathrm{k}_{1}= & \text { thermal conductivity of rock solids } \\
\mathrm{k}_{2}= & \text { thermal conductivity of saturating fiuid } \\
\mathrm{m}= & \text { an empirical exponent }=\mathrm{C} \phi \\
& \text { where } \phi \text { is fractional porosity } \cong 1.0 \\
& \mathrm{C} \text { is a correlation factor } \cong 1.0
\end{aligned}
$$

C. Rock Mechanical Behavior

General Discussion. Experiments have confirmed the theoretical predictions that a rise in temperature generally lowers the rock strength and increases the ductility and flow tendency of rock (Figures 1 and 2). Specifically, these include work by Handin and Hager [44] on sandstones, siltstones and other rocks at various confining pressures and temperatures; Griggs, Turner and Heard [43] on marble granite and limestone over a temperature range of 500 to $800^{\circ} \mathrm{C}$; Le Comte [50] on artificial polycrystalline rock salt crystal at temperatures between 30 and $300^{\circ} \mathrm{C}$; Serdengecti and Boozer [70] on sandstone, limestone and gabbro at temperatures 25 to $150^{\circ} \mathrm{C}$; and Lomenick and Bradshaw [53] on scaled models of rock salt pillars.

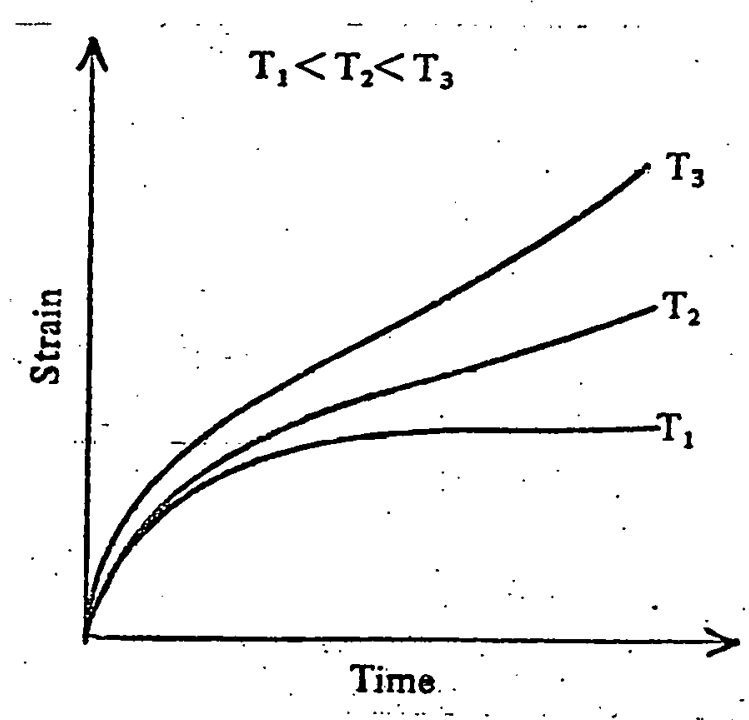

Figure 1. Effect of Temperature in Creep [18? 
Figure 2. Stress-Strain Curves for Repetto Siltstone Deformed Dry in Compression at 1,000 and 2,000 Bars Confining Pressure and at Different Temperatures [40:]

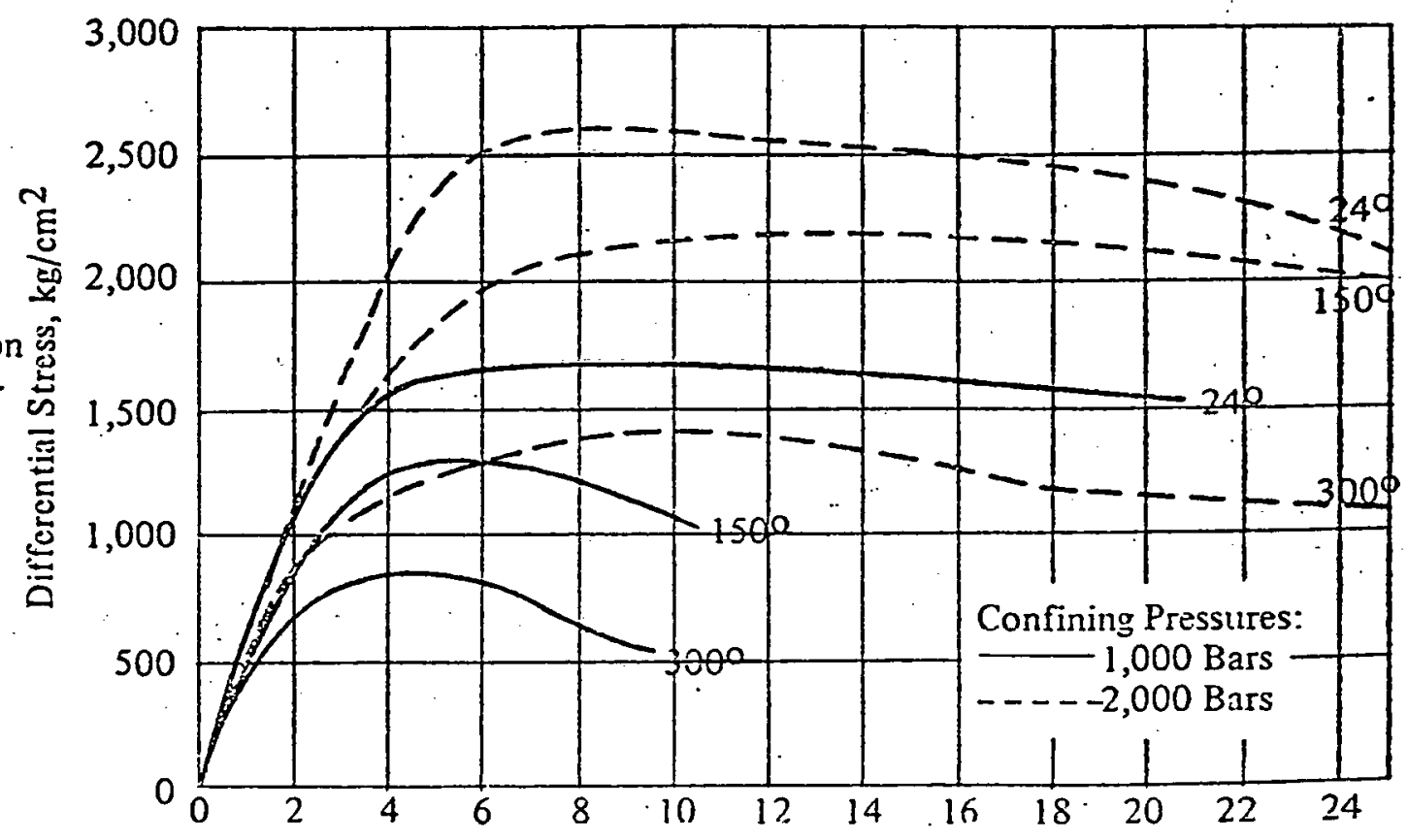

Strain. Percent

It has been found by other investigators that the deformation characteristics of rock are very dependent upon the rate of stress increase and there is a tendency for rock ductility to increase with decreasing stress rate [80]. Secondly, the temperature increase of the rock itself will cause the rock exposed to the highest temperature changes to have higher ductility.

Thermal spalling is a phenomen characterized by the separation of thin layers of material as a result of the application of heat to the surface of a solid mass such as a rock. Two distinct cases of spalling are possible, depending on the conditions of heating [42]:

1. Spalling Due to a Very High Rate of Heating. This corresponds to the condition known as thermal shock where a very thin layer at the heated surface is affected by temperature changes. Under this condition, the occurrence of thermal spalling depends upon the temperature level reached at the surface. For a given material, spalling takes place as the critical temperature for that material is reached. The critical temperature may be estimated as [42] :

$$
T(s)=\frac{P_{u}(1-v)}{E a}
$$

where $P_{u}$ is the compressive strength of the material, and $E, \nu$ and $a$ are the modulus of elasticity, Poisson's ratio, and the coefficient of thermal expansion. 
2. Spalling Due to a Slow Rate of Heating. In this case, failure is governed by the temperature gradient rather than by the maximum temperature attained at the surface. It is thus possible to reach very high surface temperatures without causing failure, provided that the rate of heating (heat $f(u x$ ) and thus the maximum temperature gradient within the rock are low enough. Even then, failure would also be dependent upon the existing structural conditions of the body (constraints and initial stresses).

Tests performed by Thirumalai [76] on three different types of rock - Sioux quartzite, charcoal granite and Dresser basalt - were in the category of rapid heating. The heat flux used in these experiments is of the order of 540,000 $(B t u) /\left(h r f t^{2}\right)$ and was produced by an oxygen-hydrogen torch. The average thermal gradient obtained in the sioux quartzite, which has the greatest amount of spalling, was about $200^{\circ} \mathrm{C} / \mathrm{mm}$. The maximum temperatures during spalling were of the order of $200^{\circ} \mathrm{C}$ and the thickness of "heat layers" on the order of $1 \mathrm{~mm}$. Discussing the spalling mechanism, Thirumalai points out that the factors on which spalling would depend are the shear strain, coefficient of expansion, thermal gradient and the shear strength of the rock.

Spalling due to both rapid and slow heating conditions was investigated by Gray [42]. In the latter case, the rock was a competent granite paragneiss and the heat source consisted of diesel exhaust gases. The spalling had occurred for an estimated rate of heating of 1 (Btu)/(hr $\left.\mathrm{ft}^{2}{ }^{\circ} \mathrm{F}\right)$ for a temperature of $600^{\circ} \mathrm{F}$.

Creep behavior and long term stability are two additional material factors to be considered for the rock media under analysis. It is fair to state that all rocks exhibit a time dependent behavior under constant loading. On the basis of the fact that granites, limestones, and shales often show very limited time dependent strain under normal temperature conditions, their time dependent properties are usually not included in engineering analyses. The same statement cannot be made, however, for such rocks as salts and evaporites. In fact, most studies relating to the effect of temperature changes on rock creep have been performed on rock salt but no data are presently available on the creep behavior of granites, limestones, and shales under the range of temperatures expected in the waste storage facility.

Application to the Rock Media of Interest. Granites are very hard, massive rocks, possessing high uniaxial compressive strength and average modulus ratio (Figure 3). Their tensile strength is many times smaller than the corresponding compressive strength. Granitic rock masses can often be characterized by such factors as large natural horizontal stresses and fractures due to unloading, with a tendency toward chemical weathering. The following considerations refer to a rock mass which is defined as "solid" in its very original state. 


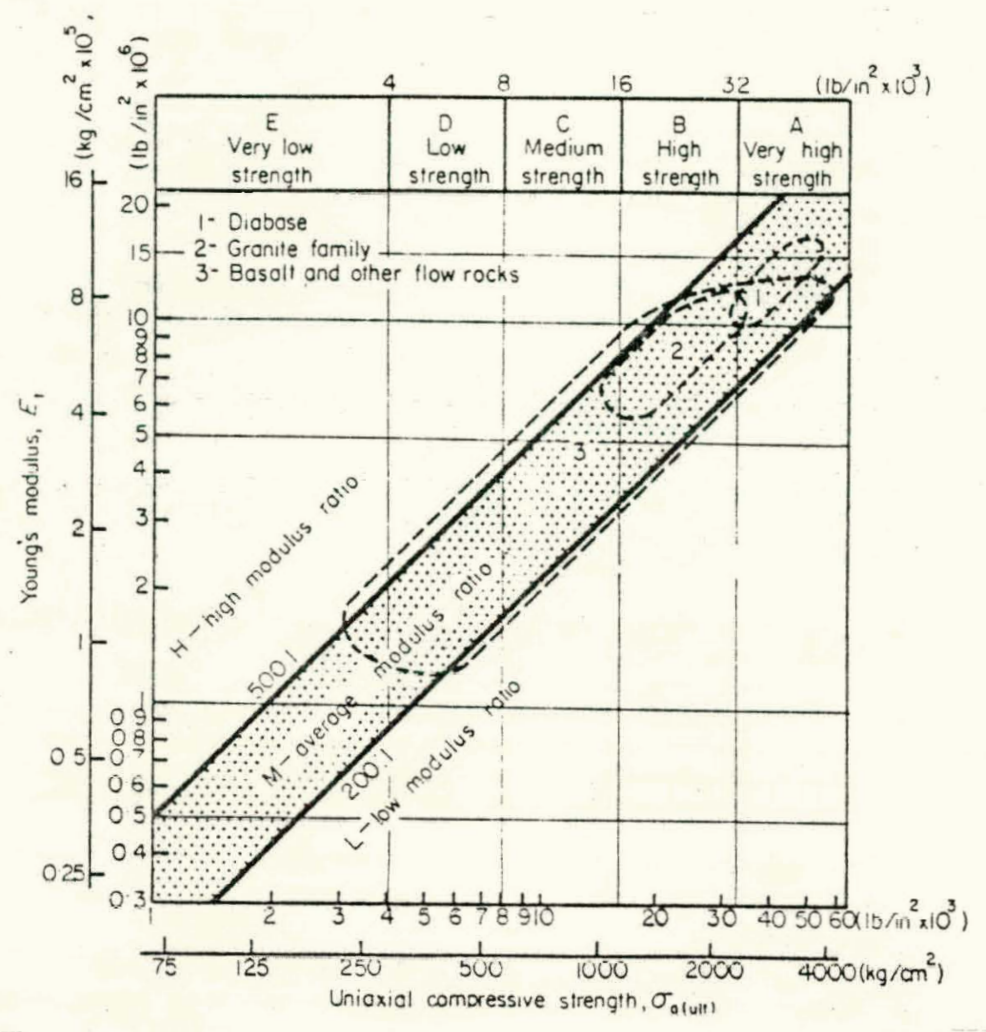

Figure 3 - Ingineering classiricetion for intact rock summary plot for igneous rocks (Deere, 1968).

At normal temperature, the stress strain curve is approximately linear and exhibits brittle behavior.*

*According to Jaeger and Cook (1969), a material is in a ductile state as long as it can sustain permanent deformation without losing its ability to resist load. Conversely, a material is in a brittle state when its ability to resist load decreases with increasing deformation. 
Initiation of stable fracture propagation, unstable fracture propagation, and strength failure are phenomena which are often associated with testing of granites under both uniaxial and triaxial compressive loading conditions (see Figure 4 for definition of terms). A nonlinear behavior due to the presence of microcracks and microfissures is also experienced for very small strains. The nonlinearity due to the presence of microcracks, however, has a tendency to disappear with an increase of applied stresses.

The thermal weakening effects on rocks, frequently referred to in fragmentation studies as "thermal fragmentation modes", depend on the following:

i) variation of physical properties with temperature

ii) phenomena such as spallation, intergranular cracks growth, chemical changes, and the expansion of entrapped gases and moisture.

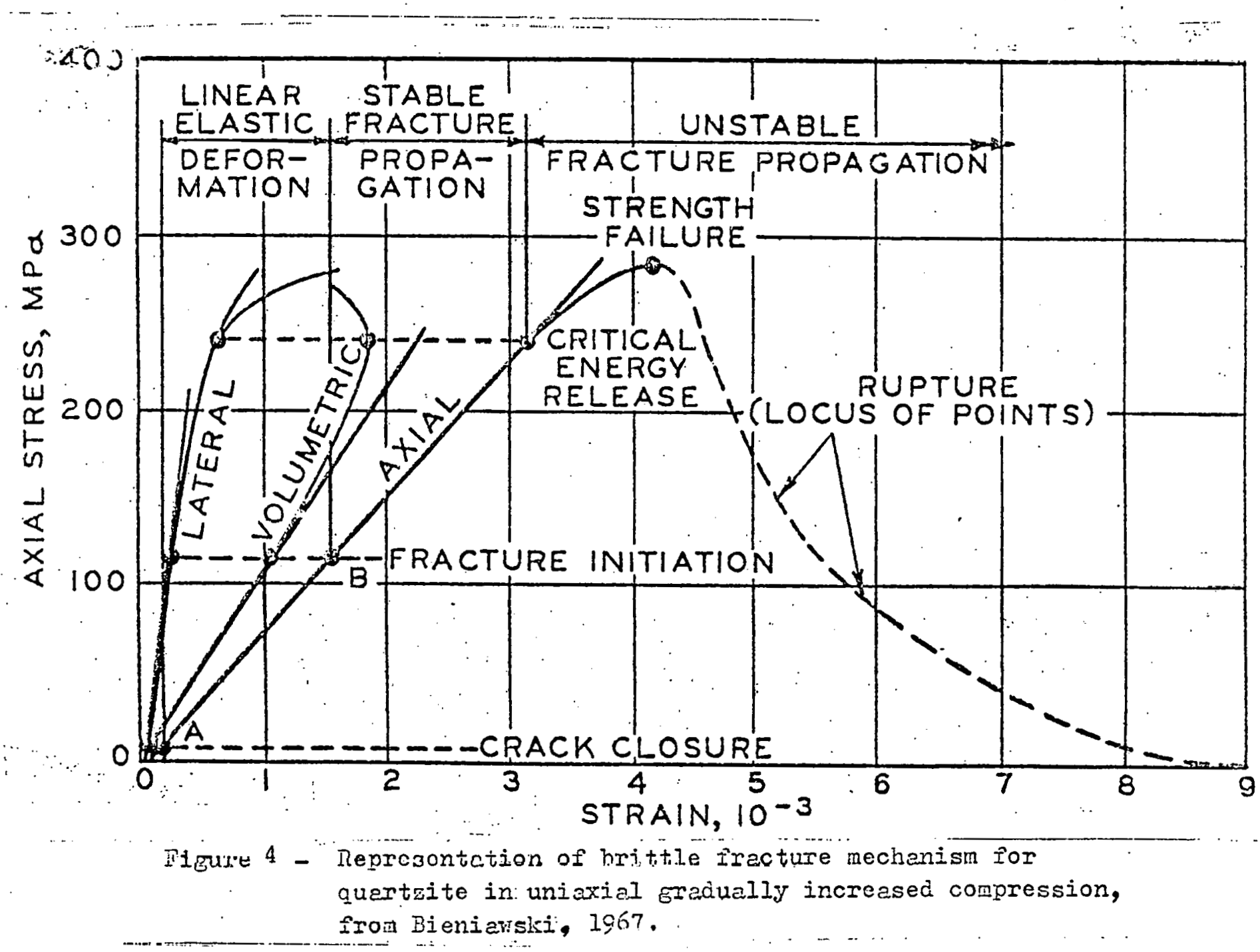


Properties to be included in analysis and design of rock structures in a temperature dependent environment include: thermal conductivity, diffusivity, coefficient of thermal expansion, deformability properties (constitutive equations $E$ and $v$, when a linear elastic behavior is assumed) and strength properties (i.e. fracture, failure, yield criteria). The effect of temperature on thermal conductivity and diffusivity, discussed in the preceding section, may be summarized briefly as causing a decrease in conductivity with increasing temperature (Figure 5). According to experimental evidence, the variation of density with temperature is negligible in relatively nonporous rocks such as granites. It is noted that the temperature dependence of specific heat has been shown to be strongly influenced by the percentage of quartz: for granites a break in the specific heat versus temperature curves (Figure 6 ) occurs at $573^{\circ} \mathrm{C}$.

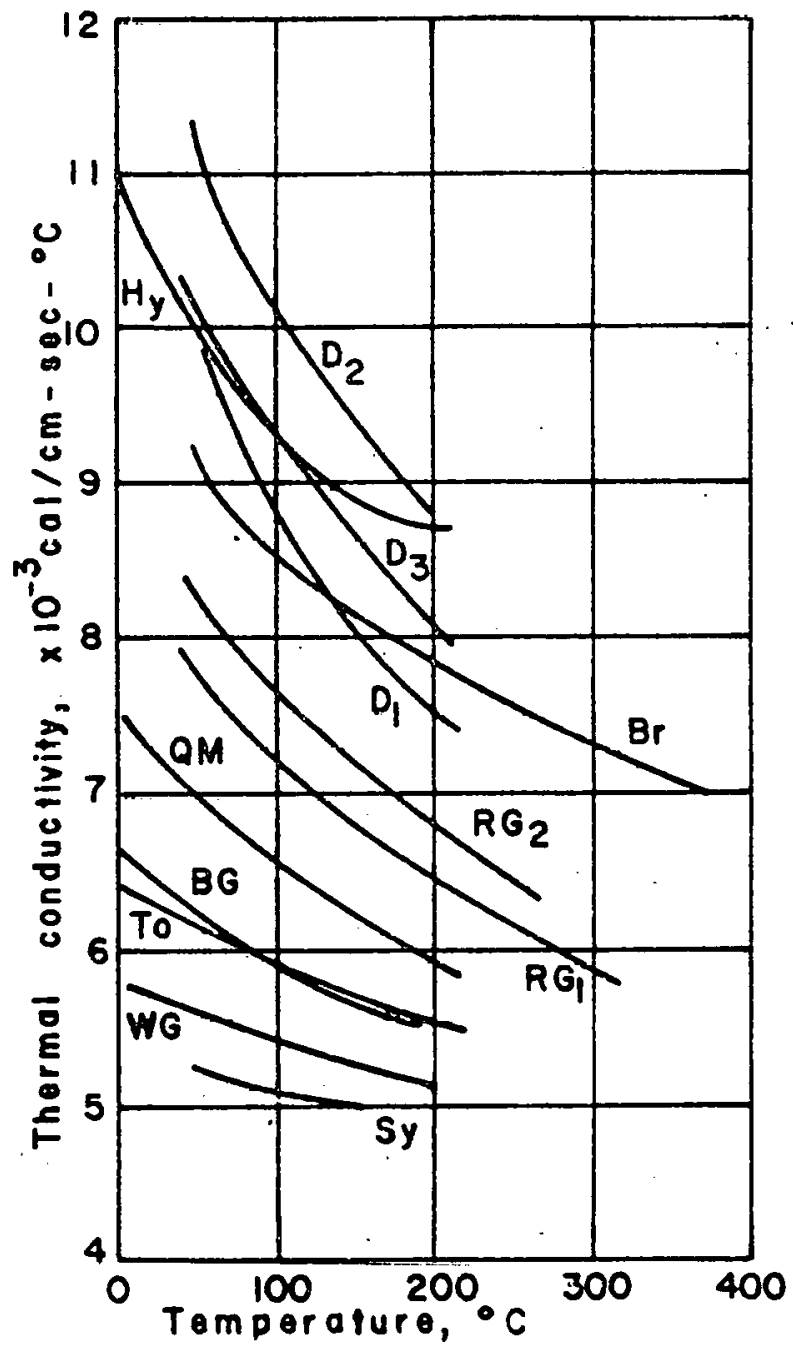

Sy Syenite, Ontario

WG Westerly Granite

To Tonalite, Calif.

BG Barre Granite

QM Quartz Monzonite, Calif.
RG Rockport Granite

$\mathrm{Br}$ Bronzitite

Hy Hypersthenite

D Dunite

Tigure 5-Thermal oonductivity of holocrystalline rocks (Birch and Clark, 1940 - see Clark at Al., 1973) 


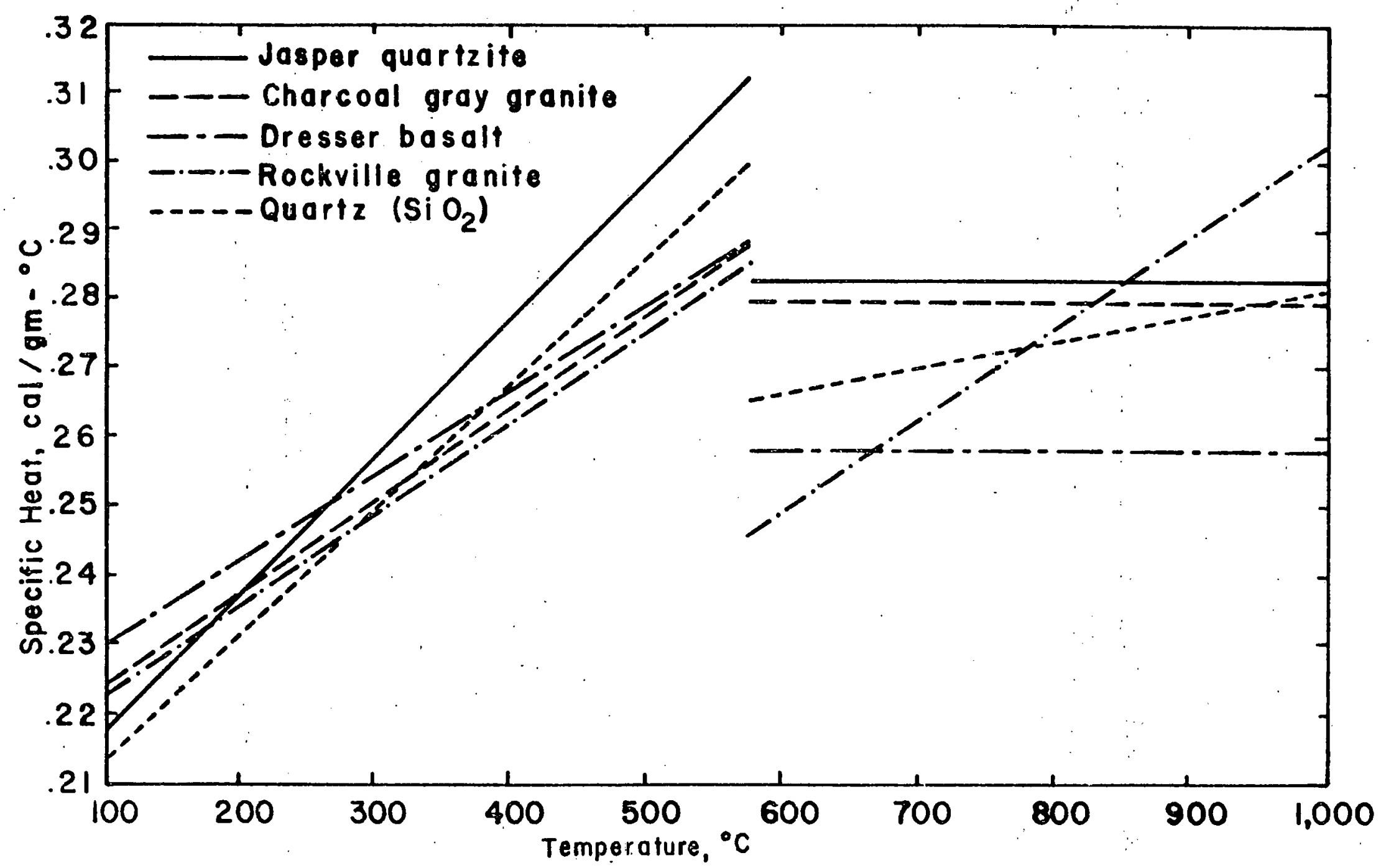

Figure 6 - Specific heat values of high - Si 0 rock types (Lindroth and Krevea, 1971 - see Clärk et Al., 1973) 
Fairly high coefficients of thermal expansion are exhibited by granites, with a tendency to expand more in one direction than in others. This phenomenon can be explained on the basis of the preferred orientations of feldspar and quartz [79].

According to the available experimental evidence (see, for example, Baidyuk, 1967), granites show a steady decrease in the yield point with temperature increase (see Table 1 and $2)$. It is noted that in the range $25^{\circ} \mathrm{C}-200^{\circ} \mathrm{C}$, the change in the tangent elastic modulus can be considered as negligible for engineering design purposes. With reference to the present problem, the effect of lowered yield strength in granites is therefore very localized in nature, probably in the near vicinity of drill holes containing the waste canisters.

TABLE 1

Elastic properties of granites vs temperature change (Baidyuk, 1967)

Elastic properties $\quad t=25^{\circ} \mathrm{C} \quad t=500 \mathrm{~atm} \quad 0^{\circ} \mathrm{C}$

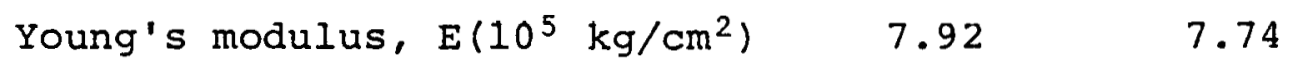

Shear modulus, $G\left(10^{5} \mathrm{~kg} / \mathrm{cm}^{2}\right) \quad 3.15 \quad 3.07$

Bulk modulus, $\mathrm{K}\left(10^{5} \mathrm{~kg} / \mathrm{cm}^{2}\right) \quad 5.43 \quad 5.37$

Poisson's ratio, $v \quad 0.257 \quad 0.260$

TABLE 2

Elastic properties of a Charcoal granite (Thirumalai, 1974)

$\mathrm{T}\left({ }^{\circ} \mathrm{C}\right) \quad \mathrm{E}\left(10^{6} \mathrm{~N} / \mathrm{m}^{2}\right) \quad v$ (Poisson's ratio)

\begin{tabular}{rrr}
\hline 24 & 77.2 & 0.20 \\
122 & 67.4 & 0.15 \\
260 & 39.2 & 0.03 \\
371 & 23.2 & -0.04 \\
482 & 15.7 & -0.06 \\
538 & 10.9 & -0.10 \\
593 & 5.8 & -0.07 \\
\hline
\end{tabular}

Limestones and shales are sedimentary rocks exhibiting compressive strengths which are generally smaller than those for igneous rocks (Figure 7). In Figures 7 and 8 it can be seen that limestones fall mostly in the high strength category and in the zone of average to high modulus ratio. Shales extend into the zone of low modulus ratio as a result of anisotropy created by bedding and laminations. These rocks often show a transversely isotropic behavior for thermal properties, deforma- 
bility, and strength. With respect to shale, it should be noted that there are a great variety of rock types: cemented and compacted shales, for example, can be as different mechanically as soil and rock.

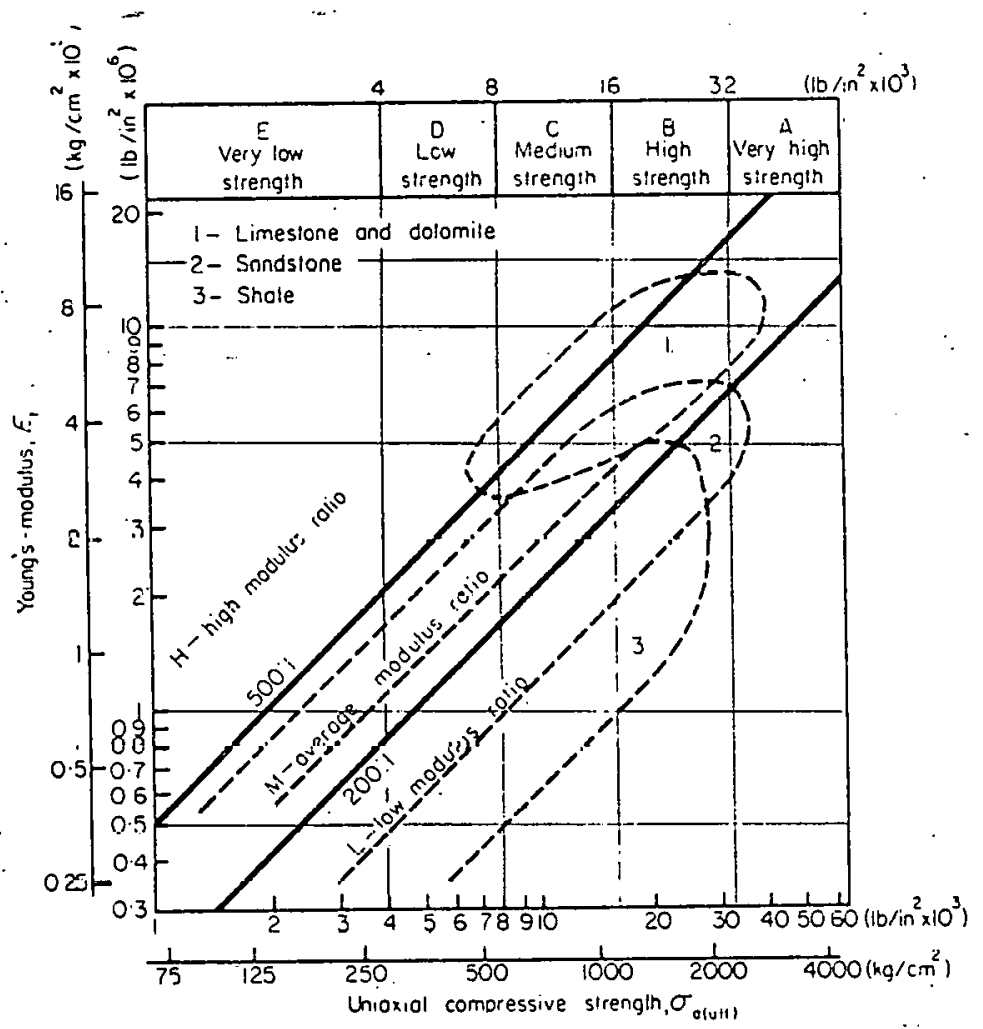

Figure 7 - Engineering classification for intact rock sumiary plot for sedinentary rocks (Deere, 1968).

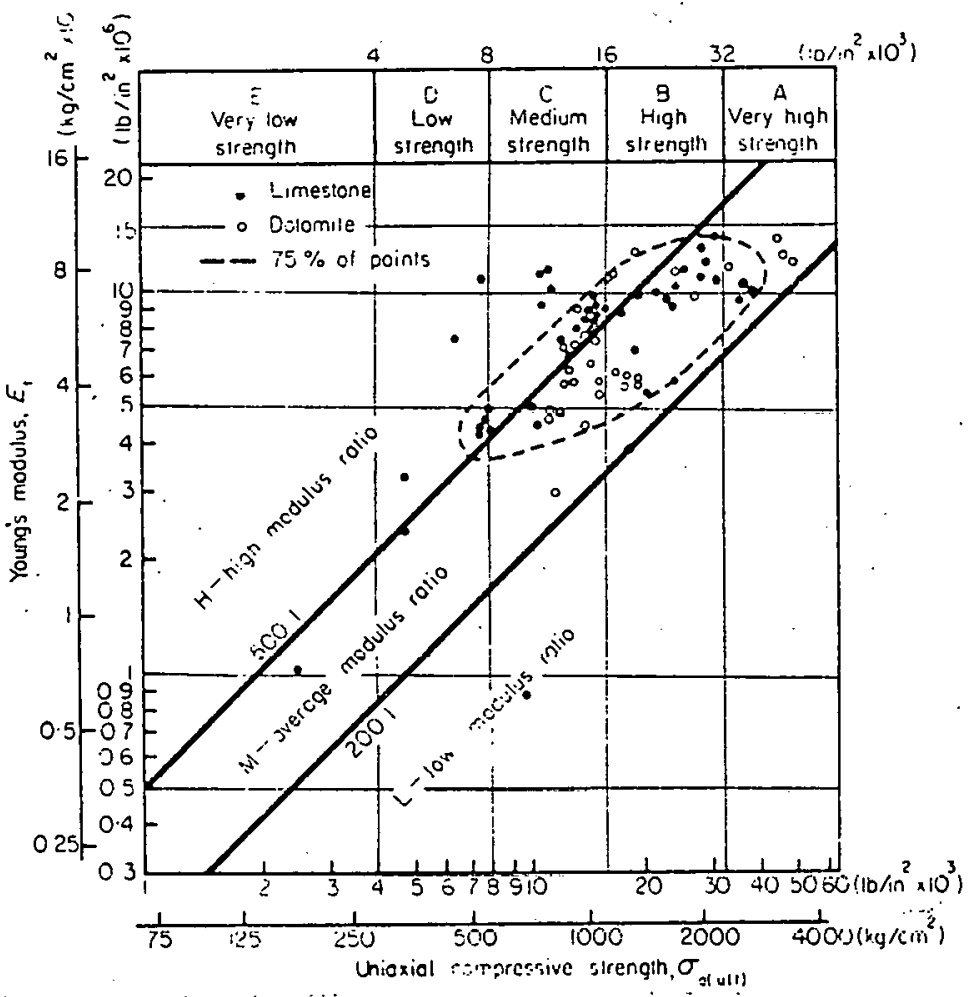

Pi,fure 8 - Ingineering classification for intact rock linestone and dolomite.(Deere, 1968). 
Experimental data on the behavior of limestones and particularly of shale, under various temperature conditions, are quite limited. Even in fragmentation studies these rocks have not yet received much attention. The data available for Solenhofen limestone (a very fine grained rock, $0.005 \mathrm{~mm}$ ) show that the deformability is not very strongly influenced by a temperature increase, at least in the range $25^{\circ} \mathrm{C}-200^{\circ} \mathrm{C}$. For example, the tangent elastic modulus only changes from $6.33 \times 10^{5}$ $\mathrm{kg} / \mathrm{cm}^{2}$ to $6.05 \times 10^{5} \mathrm{~kg} / \mathrm{cm}^{2}$ (Table 3 ).

TABLE 3

Elastic properties of Solenhofen limestone vs temperature change (Baidyuk, 1967)

$$
\mathrm{p}=500 \mathrm{~atm}
$$

Elastic properties

$t=25^{\circ} \mathrm{C}$

$t=200^{\circ} \mathrm{C}$

$\begin{array}{lll}\text { Young's modulus, } E\left(10^{5} \mathrm{~kg} / \mathrm{cm}^{2}\right) & 6.33 & 6.05 \\ \text { Shear modulus, } G\left(10^{5} \mathrm{~kg} / \mathrm{cm}^{2}\right) & 2.37 & 2.28 \\ \left.\text { Bulk modulus, K(105 } \mathrm{kg} / \mathrm{cm}^{2}\right) & 6.43 & 5.83 \\ \text { Poisson's ratio, } v & 0.336 & 0.377\end{array}$

Additional data for limestone have recently been supplied by Olsson [61], who has investigated the dependence of frictional properties on temperature increase. He has shown that under normal pressure conditions, increasing temperature from $25^{\circ} \mathrm{C}$ to $100^{\circ} \mathrm{C}$ does not have much effect on frictional properties. At $300^{\circ} \mathrm{C}$ a relatively strong temperature effect is present in terms of increasing plasticity of gouge material or asperities with increased temperature. A temperature dependent brittle-ductile transition pressure occurs in limestone: at $25^{\circ} \mathrm{C}$, the transition pressure is $1790 \mathrm{~kg} / \mathrm{cm}^{2}$; at $100^{\circ} \mathrm{C}$, it is $1750 \mathrm{~kg} / \mathrm{cm}^{2}$; and at $300^{\circ} \mathrm{C}$, it is $1310 \mathrm{~kg} / \mathrm{cm}^{2}$.

With respect to the possible anisotropic behavior of thermal properties of limestone, some evidence is provided by Luesatja [55] for Indiana limestone ( a fine grained rock, $0.14 \mathrm{~mm}$ ). This rock exhibits a higher thermal expansion in a plane perpendicular to the bedding plane. Similar results have been previously reported by Harvey [45] for the Kimmswick and Harrodsburg limestones, which are both coarse grained. This behavior is caused by preferred orientation of calcite grains.

Discontinuities and joints play a major role as structural components of sedimentary formations. Their behavior is very difficult to assess even for natural temperature conditions and no data are known to be available in the temperature range expected for the underground waste facility. The 
infilling material and roughness of the discontinuities' surfaces have to be considered as dependent on temperature. This means that temperature dependent deformability and strength parameters should be assigned to discontinuities.

D. Chemical Properties of Rocks

Potential chemical reactions involving the rock media may be classified as follows:

1. Oxidation-Reduction Reactions

2. Generation of Volatile Components

3. Reaction between the Canister and the Rock

Elements, such as iron, found in rock can be readily reduced or oxidized with attendant structural changes, dissociation, and recrystallization. Although these reactions can affect the physical strength of rock, the problem will not be significant if the reactive elements are present in negligible quantities.

Decarbonation of rocks containing carbonates is an important reactive process, which generates the volatile components $\mathrm{CO}_{2}$ and water vapor. This reaction is hastened by the application of heat.

The third potential reaction, which concerns the canister, would become a concern only if the thermal conductivity of the rock immediately surrounding the canister were significantly underestimated.

For rocks with a high carbonate content, such as limestone, the most potentially serious chemical reaction is the generation of volatile components induced by heating. This chemical reaction is of concern because it tends to exacerbate fracture of the rock. From Table 4 it can be seen that the other two rocks of interest, shale and granite (igneous), contain very little carbonates. In our estimation, therefore, limestone is the only rock medium that would require special consideration as far as chemical reactions are concerned. 


\section{TABLE 4}

Average Chemical Composition of Rocks [29]

\begin{tabular}{|c|c|c|c|c|c|c|}
\hline $\begin{array}{c}\text { Constit- } \\
\text { uent }\end{array}$ & $\begin{array}{l}\text { Igneous } \\
\ddots\end{array}$ & Shale & Sands tone & Limestone & Sediment ${ }^{a}$ & Sediment $^{b}$ \\
\hline $\mathrm{SiO}_{2}$ & 59.14 & 58.10 & 78.33 & 5.19 & 57.95 & 44,5 \\
\hline $\mathrm{TiO}_{2}$ & 1.05 & 0.65 & 0.25 & 0.06 & 0.57 & 0.6 \\
\hline $\mathrm{Al}_{2} \mathrm{O}_{3}$ & 15.34 & 15.40 & 4.77 & 0.81 & 13.39 & 10.9 \\
\hline $\mathrm{Fe}_{2} \mathrm{O}_{3}$ & 3.08 & 4.02 & 1.07 & 0.54 & 3.47 & 4.0 \\
\hline $\mathrm{FeO}$ & 3.80 & 2.45 & 0.30 & - & 2.08 & 0.9 \\
\hline $\mathrm{MgO}$ & 3.49 & 2.44 & 1.16 & 7.89 & 2.65 & 2.6 \\
\hline $\mathrm{CaO}$ & 5.08 & 3.11 & 5.50 & 42.57 & 5.89 & 19.7 \\
\hline $\mathrm{Na}_{2} \mathrm{O}$ & 3.84 & 1.30 & 0.45 & 0.05 & 1.13 & 1.1 \\
\hline $\mathrm{K}_{2} \mathrm{O}$ & 3.13 & 3.24 & 1.31 & 0.33 & 2.86 & 1.9 \\
\hline $\mathrm{H}_{2} \mathrm{O}$ & 1.15 & 5.00 & 1.63 & 0.77 & 3.23 & - \\
\hline$P_{2} O_{5}$ & 0.30 & 0.17 & 0.08 & 0.04 & 0.13 & 0.1 \\
\hline $\mathrm{CO}_{2}$ & 0.10 & 2.63 & 5.03 & 41.54 & 5.38 & 13.4 \\
\hline $\mathrm{SO}_{3}$ & - & 0.64 & $0: 07$ & 0.05 & 0.54 & - \\
\hline $\mathrm{BaO}$ & 0.06 & 0.05 & 0.05 & - & - & - \\
\hline$C^{-:}$ & - & 0.80 & - & - & 0.66 & - \\
\hline Mn 0 & - & $\therefore$ & - & - & $\div$ & 0.3 \\
\hline Total.... & 99.56 & 100.00 & 100.00 & 99.84 & 99.93 & 100.0 \\
\hline
\end{tabular}

${ }^{a}$ Shale 82 , sandstone 12,1 imestone 6 ; after Leith and Mead.

boldervaart, Geol. Soc. Amer. Spec. Paper 62, 132, 1955. 


\section{RESULTS}

The physical, mechanical, thermal, chemical, rock mass, and behavioral properties for the four types of rock are given in Table 5. The following discussion is based on the thermal analysis performed by Cheverton and Turner [28] for a salt medium, as well as the values given in the table.

The main thermal criterion for comparing qualitatively the canister spacings in different rock media is that the temperature inside the canister should remain below the temperature of the waste solidification process. This criterion ensures the thermal stability of the waste. Other thermal criteria developed by Cheverton and Turner were related to rock mechanics considerations exclusively applicable to bedded salt formations; hence, they were not included in this general comparison.

The temperature field around the canister may be divided into three regions: near field, intermediate field, and far field. Cheverton and Turner's previous study for waste storage in salt indicated that the near field extends one or two feet from the canister and is distinguished by a very large temperature gradient; the intermediate field lies between. two and four feet from the canister and its temperature gradient is about one tenth that of the near field; the far field extends beyond four feet from the canister and its temperature gradient is only a few degrees ( $F$ ) per foot. Therefore, it can be concluded that severe temperature rise is a near field phenomenon only, and this phenomenon will determine canister spacing when allowable waste temperature is the dominant criterion.

\section{A. Granite}

The thermal conductivity of granite is about half that of salt. Heat conduction in granite, therefore, is expected to be a good deal worse than in salt, and the temperature gradient in granite will be corresondingly higher than that for salt. This implies that temperature inside the canister and immediately surrounding the canister can be significantly higher for granites as the host rock than for salt. Moreover, conductivity will decrease with temperature, thus further retarding near field heat transfer and tending to elevate the temperature inside the canister. This near field effect could eventually cause temperatures to exceed the allowable temperature of the waste, regardless of the canister spacing. Should detailed analysis prove this to be the case, either the power output of the canister would have to be reduced or the canister design criteria would have to be reevaluated. 
TABLE 5

ROCK THERMOPHYSICAL PROPERTIES AND BEHAVIOR

\begin{tabular}{|c|c|c|c|c|c|c|}
\hline & Properties & Units & Salt & Granite & Limestone & Shale \\
\hline \multirow[t]{11}{*}{ Physical } & Density & $\mathrm{gm} / \mathrm{cm}^{3}$ & 2.16 & $2.59-2.88$ & 2.60 & $2.67 \sim 3.01$ \\
\hline & Moisture Content & & Low & Low & Dry Saturated & Dry-Saturated \\
\hline & Porosity & 8 Void & Non-Porous & Non-Porous & $0.4225 .6(3.6$ Mean $)$ & $3.4 \sim 43.0(13.2$ Mean $)$ \\
\hline & Solubility in water & \& Solvent & High & Low & Low & Low \\
\hline & Shear Modulus & $10^{11_{\text {Dynes }} / \mathrm{cm}^{2}}$ & Low & $0.79-3.9(2.5$ Mean $)$ & $1.2-3.0(2.5$ Mean $)$ & $1.2 \sim 2.5(1.5$ Mean $)$ \\
\hline & Young's Modulus & $10^{11}$ Dynes $/ \mathrm{cm}^{2}$ & 0.5 & $2.13-6.1(4.5$ Mean $)$ & $1.7-8.0(6.5$ Mean $)$ & $1.2 \cdot 4.4(2.0$ Mean $)$ \\
\hline & Poisson Ratio & & 0.5 & 0.31 & 0.24 & $0.04 \sim 0.12$ (0.08 Mean) \\
\hline & Compressive Strength & $10^{9}$ Dynes $/ \mathrm{cm}^{2}$ & 0.5 & $0.7 \sim 2.8$ & $0.2 \sim 2.0$ & $0.07-1.7$ \\
\hline & Tensile Strength & $10{ }^{9}$ Dynes $/ \mathrm{cm}^{2}$ & 0.01 & $0.04 \sim 0.14$ & $0.02 \sim 0.14$ & $0-0.1$ \\
\hline & Cohesion & $10^{9}$ Dynes $/ \mathrm{cm}^{2}$ & Not Available & $0.10 \sim 0.40$ & $0.04 \sim 0.35$ & $0.02 \sim 0.28$ \\
\hline & Angle of Friction & Degrees & Not. Available & $51 \sim 58$ & $37 \sim 58$ & $30 \sim 45$ \\
\hline \multirow[t]{4}{*}{ Thermal } & Thermal Conductivity & $\mathrm{Cal} /\left(\sec \mathrm{cm}^{\circ} \mathrm{C}\right)$ & $13.1 \times 10^{-3}$ & $5.2 \sim 9.0 \times 10^{-3}$ & $2.1 \sim 7.3 \times 10^{-3}$ & $2.8 \sim 8.4 \times 10^{-3}$ \\
\hline & Heat Capacity & $\mathrm{Ca} 1 /\left(\mathrm{gm}^{\circ} \mathrm{C}\right)$ & $\begin{array}{l}0.19 \text { (Solid); } \\
0.27 \text { (Liq.) }\end{array}$ & $0.16 \sim 0.33$ & 0.20 & 0.16 \\
\hline & Critical Pressure & $\mathrm{Kg} / \mathrm{cm}^{2}$ & Not Available & Not Available & $1310\left(300^{\circ} \mathrm{C}\right)$ & Not Available \\
\hline & $\begin{array}{l}\text { Linear Ther. Expan. } \\
\text { Coeff. }\end{array}$ & Per ${ }^{\circ} \mathrm{C}$ & $\begin{array}{r}40.40 \times 10^{-6}\left(40^{\circ} \mathrm{C}\right) \\
3.67 \times 10^{-6} \text { (Liq.) }\end{array}$ & $8 \pm 3 \times 10^{-6}\left(20^{\circ}-100^{\circ} \mathrm{C}\right)$ & $8 \pm 4 \times 10^{-6}\left(20^{\circ}-100^{\circ} \mathrm{C}\right)$ & app. $8 \times 10^{-6}$ \\
\hline \multirow[t]{2}{*}{ Chemical } & Chemically Reactive & & No & No & Highly & Low \\
\hline & Phase Change (Melt.) & ${ }^{\circ} \mathrm{C}$ & 804 & $1152 \sim 1305$ & $1482 \sim 1759$ & app. 1100 \\
\hline \multirow[t]{9}{*}{ Rock Mass } & Brittleness & & No & Yes & Yes & Yes/No (Depends on Comp.) \\
\hline & $\begin{array}{l}\text { Inelasticity } \\
\text { (Viscoelasticity) }\end{array}$ & & Yes & No Prom $25^{\circ} \mathrm{C}$ to $200^{\circ} \mathrm{C}$ & No From $25^{\circ} \mathrm{C}$ to $200^{\circ} \mathrm{C}$ & $\begin{array}{l}\text { No at } 25^{\circ} \mathrm{C} ; \\
\text { Yes at } 200^{\circ} \mathrm{C}\end{array}$ \\
\hline & Homogenej.ty & & High & High & High & No \\
\hline & Isotropy & & High & Moderate & Low & No \\
\hline & An isotropy & & Low & Low & Moderate & $\mathrm{High}$ \\
\hline & Transverse Isotropy & & No & No & Moderate & $\mathrm{High}$ \\
\hline & Orthotropy & & Low & Moderate & Moderate & Moderate \\
\hline & Continuity & & High & $\mathrm{High}$ & Moderate & No \\
\hline & Diṣcuntinuities & & No & Low & Moderate & $\mathrm{High}$ \\
\hline \multirow[t]{3}{*}{ Behavioral } & Creep & & $\mathrm{High}$ & Low & Low & Low to Moderate \\
\hline & Coupling Direction & & strong & strong & strong & strong \\
\hline & $\begin{array}{l}\text { (Mcchanical and } \\
\text { Thermal) }\end{array}$ & & Therm. $\longrightarrow$ Mech. & Therm. $\underset{\text { weaks }}{\longrightarrow}$ Mech. & Therm. $\underset{\text { Strong }}{\rightleftarrows}$ Mech. & Therm. $\underset{\text { strong }}{\rightleftarrows}$ Mech. \\
\hline
\end{tabular}




\section{B. Limestone}

The thermal conductivity of limestone is about the same as that of granite, and the same general observations pertaining to canister spacing in granite therefore apply to limestone. However, containment of the waste in limestone poses an even greater problem: the decrease in limestone's near field conductivity, caused by increased temperature, will be lowered further as moisture in the porous rock is driven out by the heat. Furthermore, at high temperatures, release of volatile components from decarbonation will hasten fracturing of the limestone, further decreasing near field conductivity. Thus, the power output of the canister would have to be reduced even more for limestone as compared to granite.

\section{Shale}

Again, the average thermal conductivity of shale is about the same as that for limestone and granite. The highly anisotropic and inhomogeneous nature of shale, however, implies that its heat transfer characteristics are very different in the direction of the strata compared to the direction perpendicular to the strata. Therefore, although guidelines for spacing the canisters in shale will be very similar to guidelines for granite, extra care must be taken to avoid propagating discontinuities and fragmentation along shale's bedding planes. These voids would cause further decreases in near field thermal conductivity and, therefore, tend to increase the temperature of the waste. 


\section{RECOMMENDATIONS FOR FUTURE INVESTIGATION}

\section{A. Rock Properties and Behavior}

We recommend that a separate investigation be conducted to develop a comprehensive understanding of the thermophysical properties and behavior of the candidate rock media. This recommendation stems from awareness of the extreme variation exhibited by rock properties and behavior, particularly as they are affected by their own thermomechanical coupling. The investigation should also provide a probabilistic description of the extent to which uncertainties in the thermophysical parameters of the system will affect the overall thermal and mechanical response of the storage facility.

The literature survey conducted for this report should be extended to include further contacts with prominent university researchers, particularly in the field of thermophysical properties; the Canadian Department of Energy, Mines and Resources; the U.S. Army's Cold Regions Research Engineering Laboratory: and the Los Alamos Scientific Laboratory. Our own experience has shown that universities, agencies, and private research organizations frequently possess valuable, in-house or interim documents not listed in any library or information retrieval system.

We also believe very strongly that theoretical investigations into rock behavior must be accompanied by an extensive testing program. The program should cover both thermal properties particularly conductivity - and rock mechanics - particularly creep behavior - with the objective of correlating and quantifying conductivity and strain (rate) as a function of all the parameters discussed in Section III.

In order to siluulate pillar behavior, tests should be performed under conditions of constant uniaxial loading with end restraints. The following variables should be considered:

1. Size and width/height ratio of the pillar

2. Pillar shape

3. Rock type

4. Presence of discontinuities in the pillar, and rock orientation

5. Temperature, i.e., specimens should be tested at different temperatures, according to preliminary predictions from the thermal analysis.

other tests, such as triaxial loadings, can also be performed in order to obtain some insight into general material behavior. 
The results of laboratory analyses should be substantiated by measurements performed in the field. The use of a properly chosen rock mechanics instrument network will allow the analysis of the behavior of the rock structure while undergoing changes due to temperature variation and excavation sequences.

B. Model Development

As previously mentioned, the theoretical analysis of a facility in rock is complicated by a number of factors not ordinarily encountered in more typical engineered structures. Rock is heterogeneous, it has properties that vary with direction (anisotropic), it is discontinuous (fractures and joints), and many of its properties are temperature and time-dependent. For the more usual types of facilities in rock, appropriate approximations, experience and engineering judgment are sufficient for analysis purposes. Although substantial strides have been made in recent years, the design of facilities in rock is still more art than science. For example, "tributary area" methods [32] and "face elements" methods $[34,68,71]$ though providing reasonable approximations, are unable to account directly for non-linear behavior, inhomogeneity of the rock mass, the presence of discontinuities, and so one.

However, because of 1) the thermal/internal pressure/lithostatic/hydrostatic load interactions, 2) the necessity to determine how structural response affects thermal stability and 3 ) the exceptionally long period of time that the integrity of the storage facility must be maintained, something more than the usual approximations, experience and judgment must be employed. The facility should be analyzed as a complete system, taking into account the interaction of as many of the factors given above as possible.

A "finite element" computer modeling technique $[14,15,16,66]$ is recommended for use in the evaluation of underground storage facility thermal characteristics, the simulation of inelastic phenomena, the examination of elastic phenomena associated with the facility's structural stability, and the thermal stability of waste contained in the canisters.

Although it naturally has some limitations of its own, the finite element method does not suffer from the severe restrictions that most other approaches are subject to. Availability and results which have already been achieved in the analysis of many rock mechanics problems suggest use of the method for the design of a mine pillar layout $[62,63]$. The possibility, at present, of solving both the thermal distribution and stress analysis problems by the same technique is to be considered another advantage.

The finite element method can be applied by performing the following sequential analyses at each time step: 
1. Three-dimensional thermal analysis of the complete structure with temperature dependent material properties.

2. Three-dimensional non-linear stress analysis to be performed on the basis of the known temperature distribution obtained above. Analyses should be carried out as follows:

a. in granite rock masses: predictions of fracture initiation based upon Griffith and modified Griffith criteria $[10,19]$; stress-strain relationship, presented by a variable-moduli approach.

b. in shales and limestones: application of an elastoplastic approach while accounting for the anisotropic behavior of both deformability and strength properties; introduction of the influence of discontinuities and joints by the use of an appropriate joint element.

In any case, the very favorable simulation techniques available with the finite element method should be used in order to follow as closely as possible the excavation and placing of the waste canisters sequence.

The following steps should be analyzed:

1. pre-excavation stage

2. rooms excavated according to a known geometric pattern

3. holes drilled for waste canisters

4. waste canisters placed in holes

5. temperature changes

6. analysis of mine structure (changing in its geometry due to progress of excavation at varions times)

It is re-emphasized that the most accurate approach is an iterative one whereby thermal and stress analyses are executed simultaneously to the point that a first solution is attained.

C. Development of a Thermal. Design Guide

A thermal design guide, to be used for the planning, design, construction and operation of underground radioactive waste material storage facilities, should be the ultimate objective of future investigations. The content of this design guide should address all the thermal aspects of disposal of these hot wastes in candidate geologic formations. The guidelines will permit basic engineering decisions to be made with a specified degree of contidence. 


\section{REFERENCES}

1. Assad, Y., "A Study of the Thermal Conductivity of Fluid Bearing Porous Rocks," Ph.D. Thesis, University of California, (June-1955).

2. Baidyuk, Bronislav Vasileuich; Mechanical Properties of Rocks at High Temperatures and Pressures, New York: Plenum Publishing Corporation, 1967.

3. Barla, G., consultant discussions with Parsons Brinckerhoff staff, September 1976.

4. Barla, G., M. Cravero and G. P. Giani, "A Numerical Method Used in Anchored Wall Design," XII Convegno Nazionale Geotecnica, Cosenza, Italy, September 1975.

5. Barla, G., M. Cravero and G. Perri, "Stability Analysis of Underground Openings Reinforced With Rock Bolts," XII Convegno Nazionale di Geotecnica, Cosenza (Italy), September 1975.

6. Barla, G., A. Garassino, and M. Jamiolkowski, "Experimental Evidence on the Contribution of Lateral Confined Plastic Flow and Creep to the settlement;" Proc. B.G.S. Conference on settlement of structures, Cambridge, April 197.4 .

7. Barla, G., G. Celoria, and M. Jamiolkowski, "Observations on the Role of Inhomogeneity in the Problem of Soil structure Interaction," 8th International Conference on Soil Mechanics and Foundation Engineering, Moscow, 1973.

8. Barla, G.,. "The Distribution of Stress Around a Single Underground Opening in a Layered Medium Under Gravity Loading." Int. J. Rock Mech. Min. Sci., 9 January 1972.

9. Barla G., "Stresses Around a Single Underground Opening Near a Traction-Free Surface," Int. J..Rock Mech. Min. Sci., 9 January 1.972 .

10. Barla G., "A Method for the-Analysis of Stress in Brittle Rock." Int. J. Rock Mech. Min. Sci., 9 January 1972.

11. Barla, G., and M. Cravero, "The Distribution of Stress Around Underground Openings Reinforced With Rock Bolts;" International Symposium on Underground Openings, September 1972.

12. Barla, G., "Applications of the Finite Element Method in the Analysis of Rock Slopes;" Conference on Natural slopes, Stability, and Conservation, Cosenza, 1971. 
13. Barla, G., "On the Distribution of Stress Around Openings Located in a Rock Mass," Doctoral Dissertation, Columbia University, New York, 1970.

14. Bathe, K. J., E. L. Wilson and R. H. Iding, "NONSAP A Structural Analysis Program for Static and Dynamic Response of Nonlinear Systems," University of California; Berkeley, California, February 1974.

15. Bathe, K. J., "Static and Dynamic Geometric and Material Nonlinear Analysis Using ADINA," Report 82448-2, Acoustic and Vibration Laboratory, Department of Mechanical Engineering., M.I.T., May 1976.

16. Bathe, K. J., "ADINA: A Finite Element Program for Automatic Dynamic Incremental Nonlinear Analysis," Report 82448-1, Acoustics and Vibration Laboratory, Department of Mechanical Engineering, M.I.T., September 1975, (revised May 1976).

17. Beck, A. E., and J. M. Beck. "On the Measurement of the Thermal Conductivity of Rocks by Observations on a Divided Bar Apparatus," Transactions of the American Geophysics Union, Vol. 61, 1958 .

18. Bedrock Technical Report, May-July, DPST-71-458, Attachment to Letter, M. H. Wahl to A. Wolman, August 11, 1971.

19. Bieniawski, Z. T., "Mechanism of Brittle Fracture of Rock," Rep. Scient. Ind: Res. South Africa, 580, 1957.

20. Birch, Francis, Thermal Considerations in Deep Disposal of Radioactive Wastes. National Research Council Publication 588, National Academy of Sciences, July 1959.

21. Birch, Francis, "Flow of Heat in the Front Range, Colorado," Bulletin of the Geological Society of America, Vol. 61, June 1950 .

22. Birch, Francis, and Harry Clark; "The Thermal Conductivity of Rocks and its Dependence on Temperature and Composition," American Journal of Science, Vol. 238, August and September 1940.

23. Bradshaw, R. L., and T. F. Lomenick, "Accelerated Deformation of Rock Salt at Elevated Temperature," Nature, V. 207 No. 4993, 1965, p. 158 .

24. Bullard, E. C., "Heat Flow in South Africa," Proceedings of the Royal Society (London), Vol. 173A, 1939. 
25. Carslaw, $\dot{H} . \mathrm{S}$. and J. C. Jaeger, Conduction of Heat in Solids, 2nd ed., Oxford University Press, 1969.

26. Carte, A. E., "Thermal Conductivity and Mineral Composition of Some Transval Rock," American Journal of Science, Vol. 253, 1955.

27. Cheverton, R. D., private communications with Parsons Brinckerhoff staff, september 15, 1976.

20. Cheverlun, R. D. and W. D. 'l'urnèr, 'l'hermal Analysis of the National Radioactive Waste Repository: Progress Through June 1971, Oak Ridge National Laboratory, 1971.

29. Clark, G. B., T. F. Lehnhoff, M. Patel and V. Allen, "An Investigation of Thermal-Mechanical Fragmentation of Hard Rock," Final Report, Rock Mechanics and Explosives Research Center, University of Missouri, 1973.

30. Clark, George B. and Terry F. Lehnhoff, "Thermal-Mechanical Fragmentation of Hard Rock for Rapid Excavation", Rock Mechanics; 1973, p. 501-555.

31. Clark, Sydney P., Jr., Handbook of Physical Constants, New York, The Geological Society of America, 1966.

32. Coates, D. F., "Pillar Loading. Part I: Literature Survey and New Hypothesis". Res. Rep. No. R158, Mines Branch, Dept. of Mines and Technical Surveys, Ottawa, 1965.

33. Crouch, S. I. and C. Fairhurst, "Mechanics of Coal Mine Bumps:," S.M.E. Transactions, Vol. 256, 1974, p. 317-322.

34. Crouch, S. L., "Two-Dimensional Analysis of Near-Surface, Single Seam Extractions", Int. J. Rock Mechanics Min. Sci., Vol. 10, No. 2, 1973, p. 85-96.

35. Deere, D. U., "Geological Considerations", Rock Mechanics in Engineering Practice, K. G. Stagg and O.C. Fienkiewcz eds., 1968, p. 1-20.

36. Dell'Amico, J. J., F. H. Captain and S. H. Chansky, "Characteristics and Thermal Conductivities of some samples of Cnasauga Shale", Report OR) L-MIT-20, Oak Ridge National Laboratory School of Chemical Enfineering Practice, Massachusetts Institute of Technology, Oak Rłdge, Tennessee, March 1967. 
37. Dmitriev, A. P., I. S. Derbenev and S. A. Goncharov, "The Thermal Properties of Rocks in a Temperature Field," Soviet Mining Science, Vol. 2, March - April 1969.

38. Empson, F. M., R. L. Bradshaw, et. al., "Results of the Operation of Project Salt Vault: A Demonstration of Disposal of High-Level Radioactive Solids in Salt", Third Symposium on Salt, Vol. 2, 1970, p. 455-462.

39. Empson, F. M., W. J. Boegly, Jr., et. al., "Demonstration of Disposal of High-Level Radioactive Solids in Salt", Second Symposium on Salt, Vol. 1, 1966, p. 432-442.

40. Freudenthal, A.M., The Inelastic Behavior of Engineering Materials and Structures, Wiley, N. Y., 1950.

41. Goodman, T., Application of Integral Methods to Transient Nonlinear-Heat Transfer, Vol. 1, Academic Press, New York, 1964, p. 51-122.

42. Gray, W. M., Surface Spalling by Thermal Stresses in Rocks, Proceedings of Rock Mechanics Symposium, University of Toronto, Mines Branch, Ottawa, 1965, p. 85.

43. Griggs, D. T., F. J. Turner, and H. C. Heard, "Deformation of Rocks at $500^{\circ}$ to $800^{\circ} \mathrm{C} "$, Geol. Soc. Amer., Memoir 79, 1960 , p. 39 .

44. Handlin, J. and R. V. Hager, "Experimental Deformation of Sedimentary Rocks Under Confining Pressure: Tests at High Temperature" , Bulletin of the American Association of Petroleum Geologists, Vol, 42, No. 12, 1958, p.2892-2934.

45. Harvey, R. D., "Thermal Expansion of Certain Illinois Limestones and Dolomites", Illinois state Geological Survey, Urbana, Circular H15, 1967, p.30.

46. Jaeger, J. C. and N. G. W. Cook, Fundamentals of Rock Mechanics, Methuen, London, 1969.

47. Jaeger, J. C., "Report on Probable Temperatures and Thermal Stresses in the Exhaust Tunnel, NORAD Project," Report on an inspection of the tunnel, July 1963.

48. Lauriello, P. J., "Application of a Convective Heat Source to the Thermal Fracturing of Rock," Int. J. Rock Mech. Min. Sci. \& Geomech. Abstr., Vol. II, 1974, p. 75-81 
49. Lawson, C. G., "Status Report: Thermophysical Properties of Rock and Rock Related Materials of Interest to the Geological Disposal Evaluation Program," Intra-Laboratory Correspondence, Oak Ridge National Laboratory, October 1975.

50. LeComte, P., "Creep in Rock Salt", J. Geol., V. 73, 1965, p. 469.

51. A. D. Little, Inc., "Methods for Measurement of Thermal Properties of Rock," Summary prepared for U.S. Army Cold Regions Research and Engineering Laboratory, May 1968.

52. Llewellyn, G., Private communications with Parsons Brinkerhoff staff, September 6, 1976.

53. Lomenick, T. F., and R. L. Bradshaw, "Deformation of Rock Salt in Openings for the Disposal of Radioactive Waste," Journal of Intl. Soc. for Rock Mechanics, Vol. 1, No. 1, 1969, p.5.

54. Loretan, H. A., "Laplace Variational Methods for Transient Multidimensional Temperature-Distributions," Nuclear Engineering and Design, No. 11, 1970, p. 27-40.

55. Luesatja, S., "Thermal Expansion and Anisotropy of Natural Building Stone," M. S. Thesis, The Pennsylvania State University, Dept. of Mine Engineering, 1976.

56. McClain, W. C., "Status of AEC Project to Establish a Salt Mine Radioactive Waste Repository," Fourth Symposium on Salt, Vol. 2, 1974, p. 337-342.

57. Mines Branch Staff, Jet Piercing Research Project, Mines Branch Investigation Report IR 62-27, Department of Mines and Technical Surveys, Ottawa, 1962.

58. Moiseyenko, U. I., L. S. Sokolova and V. Ye. Istomin, "Electrical and Thermal Properties of Rocks," National Technical Information Service, NASA Technical Translation F-671, 1970 .

59. Mossop; S. C. and G. Gafner, "The Thermal Constants of Some Rocks from the Orange Free State", Journal of the South African Institute of Mining Methods, Vol. 52, 1951.

60. Odé, Helner, "Review of Mechanical Properties of Salt Relating to Salt Dome Genesis", The Geological Society of America, Inc., Special Paper 88, 1968. 
61. Olsson, W. A., "Effects of Temperature, Pressure and Displacement Rate on the Frictional Characteristics of a Limestone," Int. J. Rock Mech. Min. Sci. \& Geomech. Abstr., Vol. 11, 1974, p. 267-278.

62. Pariseau, W. G., "Thermoelastic Plastic Analysis in Rock Mechanics," Numerical Methods in Georechanics, A.S.C.E., 1976 , p. $116 \overline{8-1187 .}$

63. Pariseau, W. G., "Limit Design of Mine Pillars Under Uncertainty," 16th Symposium on Rock Mechanics, University of Minnesota, Minneapolis, September 22-24, 1975.

64. Parsons, Brinkerhoff, Quade \& Douglas, Inc., Savannah River Plant Bedrock Waste Storage Project, Interim Preliminary Conceptual Analysis Report prepared for the U.S. Atomic Energy Commission, July 1972.

65. Pegler, A. V., "The Aeolotropy of Thermal Conductivity in Rock," Paper presented at the Third Symposium on Salt, New York, 1970.

66. Polivka, R. M. and E. I. Wilson, "Finite Element Analysis of Nonlinear Heat Transfer Problems," University of California, Berkeley, California, June 1976.

67. Richter, D. and G. Simmons, "Thermal Expansion Behavior of Igneous Rocks," Int. J. Rock Mech. Min. Sci. \& Geomech. Ábstr., Vo1. 11, 1974, p. 403-411.

68. Salamon, MD. G., "Rock Mechanics of Underground Excavations," Proceedings of the Third Congress of the International Society for Rock Mechanics, Denver, 1974, p. 951-1099.

69. Sass, J. H., Arthur H. Lachenbruch and Robert Munroe, "Thermal Conductivity of Rocks from Measurements on Fragments and its Application to Heat Flow Determination," Journal of Geophysical Research, Vol. 76, 1971.

70. Serdengecti, S., and G. D. Boozer, "The Effects of Strain Rate and Temperature on the Behavior of Rocks Subjected to "Triaxial Compression," Penn. State Univ., Mineral Industries Experiment station Bull. 76, 1961, p. 83.

71. Starfield, A. M. and S. L. Crouch, "Elastic Analysis of Single Seam Extractions," 14th Symposium on Rock Mechanics, Pennsylvania State University, June 11-14, 1972. Published by A.S.C.E., 1973, p. 421-439. 
72. Starfield, A. M. and W. C. McClain, "Project Salt Vault: A Study in Rock Mechanics, " International Journal of Rock Mechanics, Mining Science and Geomechanical Abstracts, Vol. 10,1973, p. 641-657.

73. Stephens, D. R., "High Temperature Thermal Conductivity of Six Rocks," Report UCRL-7605, University of California, Lawrence Radiation laboratory, 1963.

74. Thirumalai, K., and J. B. Cheung, "A Study on a New Concept of Thermal Hard Rock Crushing," Rock Mechanics, 1972, p. 527-554.

75. Thirumalai, K., "Potential of Internal Heating Method for Rock Fragmentation," 12th Symposium on Rock Mechanics, The University of Missouri, November 16-18, 1970. Published by A.I.M.E., 1971, p. 697-719.

76. Thirumalai, K., "The Process of Thermal Spalling Behavior in Rocks - An Exploratory Study," Rock Mechanics Theory and Practice, 1lth Symposium on Rock Mechanics, Berkeley, California, 1969, p. 705.

77. Thomas, Josephus, Jr., Robert R. Frost and Richard D. Harvey, "Thermal Conductivity of Carbonate Rocks," Engineering Geology, Vol. 7, 1973.

78. Trent, D. S. and J. R. Welty, "A Summary of Numerical Methods for Solving Transient Heat Conduction Problems", Bulletin No. 49, Engineering Experiment Station, Oregon State University, Corvallis, Oregon, October 1974.

79. Winkler, E. M. , Stone: Properties, Durability in Man's Environment, Springer-Verlag, New York, 1975, p. 230.

80. Wuerker, R. G., Influence of Stress Rate and Other Factors in Strength and Elastic Properties of Rocks, Factors Common to Communities, Underground Failure, and Failure Resulting Erom Explosions, p. 5-29.

81. U. S. Energy Research \& Development Administration, Alternatives for Manaring Wastes from Reactors and Post-Fission Operations in the LWR Fuel Cycle, ERDA 76-43, Vol. 4, May, 1976 . 